Supplement of Nat. Hazards Earth Syst. Sci., 15, 1763-1784, 2015

http://www.nat-hazards-earth-syst-sci.net/15/1763/2015/

doi:10.5194/nhess-15-1763-2015-supplement

(C) Author(s) 2015. CC Attribution 3.0 License.

(c) (1)

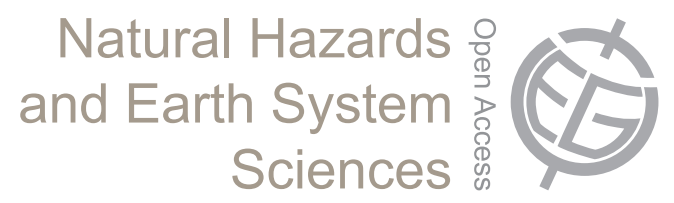

Supplement of

\title{
Scenario-based numerical modelling and the palaeo-historic record of tsunamis in Wallis and Futuna, Southwest Pacific
}

\section{G. Lamarche et al.}

Correspondence to: G. Lamarche (geoffroy.lamarche@niwa.co.nz)

The copyright of individual parts of the supplement might differ from the CC-BY 3.0 licence. 


\section{Generation of land topography and lagoon bathymetry integrated Digital Terrain Model (DTM)}

While regional seafloor topography is acceptable in deep oceanic environments, best possible accuracy is required in the coastal zone for numerical modelling of tsunami propagation. For this study, particular attention was devoted to generate two distinct DTMs for Wallis and for Futuna-Alofi. For Wallis the DTM combines a variety of existing data and new data specifically collected and processed for this project. Below we provide details on the methodology and data used to generate both DTMs.

\section{Onshore Data}

Onshore we used 1:25,000 topographic maps for Wallis (IGN, 2007b) and Futuna-Alofi (IGN, 2007a). These include the $5 \mathrm{~m}$ elevation and subsequent $10 \mathrm{~m}$ contour lines.

\subsection{Wallis land elevation}

Land elevation measurements for Wallis were collected using a Real-Time Kinematic GPS (RTK GPS) over a period of 4 days in September 2011. The instrumentation consisted of a stationary base GPS and a roving unit mounted on a car. The position of the base station was calibrated to existing survey marks at different locations around the island. The resulting accuracy was better than $5 \mathrm{~cm}$ in horizontal and vertical directions. A total of nearly 10,000 points was collected along roads and other easily accessible areas on the north, east and SE sides of the island. Measurements were limited to $15 \mathrm{~m}$ above sea level. No GPS measurements were made along the west shore due to the lack of both roads close to the shore and survey marks.

Most survey marks in Wallis are referenced to the GRS1980 ellipsoid and are not referenced to sea level heights (orthometric). Since elevations relative to sea level are required for tsunami 
modelling, survey data were converted into orthometric heights. There are only five reference marks with known orthometric heights in Wallis, which required us to calibrate each survey with 2 or 3 survey marks, using their ellipsoidal heights. The extra mark located on Nukutapu has an orthometric height of lower precision, but was introduced into the data set to extend the offset model to the south and capture the surveyed data south of Halalo (Fig. 3). The Mata-Utu B station was shifted east by ca. $1 \mathrm{~km}$ to allow for extending the offset model to cover the area of the northern beach road of Mata-Utu. The offset surface was interpolated from the difference between orthometric height and ellipsoidal height at each survey mark, using the Kriging method with exponential semivariogram, to a $30 \mathrm{~m}$ raster. The resulting surface was used to derive orthometric heights for each of the surveyed data points by applying the offset to the ellipsoidal height.

For the creation of a coastal DEM, the $0 \mathrm{~m}$ and $15 \mathrm{~m}$ contour lines were digitized from the 1:200 000 IGN topographic map and combined with the RTK GPS data to derive a detailed DEM of the zone between 0 and $15 \mathrm{~m}$ around the entire island. The interpolation was done using the Topo-to-Raster routine in ArcGIS to create a hydrologically correct DEM, preserving streams and ridges.

\subsection{Futuna land elevation}

We were unable to retrieve GPS data in Futuna and Alofi in a similar fashion as in Wallis. Instead, we used the digitised the 0,5 and $10 \mathrm{~m}$ contour lines from the 1:25,000 topographic maps (IGN, 2007a).

\section{Offshore data}

Away from the coast of Wallis and Futuna, we used the bathymetry of the Pacific Basin from the publically available GEBCO dataset.

In the vicinity of the islands, we used the SHOM bathymetric charts for Wallis (SHOM, 2008) and Futuna-Alofi (SHOM, 2010), and the multibeam bathymetry datasets acquired during the ALAUFI survey, March 2001, (Pelletier et al., 2001; Pelletier et al., 2000a) around Futuna and Alofi and the WALFUT survey, June 2011, (Pelletier et al., 2011) around Wallis.

Bathymetric data in the Wallis lagoon are sparse, with only one existing chart covering the south and SE shores at a scale of 1:20,000 (SHOM, 2008). The deepest part of the lagoon was chartered during the WALFUT project using multibeam echosounder technology and was integrated in this study. The SE, NE and NW part of the lagoon have a very limited depth 
information. For the uncharted part, we developed a remote sensing approach to estimate water depth in the lagoon, whereby images from the 13 November 2004 Quickbird satellite survey were used to predict depths based on ocean colour. The Quickbird satellite captures images in 4 spectral bands: red, green, blue and near-infrared. Ratios of different bands were tested to best match bathymetric contour lines in the mapped area of the lagoon (Fig. 1).

Best matches between the satellite images and chart depths were achieved by first "normalizing" both, the blue and green channels with the help of the red channel and subsequently calculating their ratio ( (blue/red) / (green/red) ). The result was reclassified into 255 classes and the threshold classes were identified which best corresponded to the charted water depths of 5 and $10 \mathrm{~m}$ (class 170 and 185 respectively). Depth contour lines were then interpolated based on the classified image.

Depths greater than $10 \mathrm{~m}$ could not be resolved using this method. In the NW lagoon of Wallis where no data is available (no SHOM charts) we used data from Andréfouët (2006). By using the coastline as an additional depth contour of $0 \mathrm{~m}$, an acceptable bathymetry for the entire lagoon could be generated.

The reef in Futuna was digitised from Google Earth extracts (Fig. 2) and IGN topo maps. In a final step, all data sets, land-based DEM and bathymetry were merged into two distinct DTMs for Wallis and for Futuna-Alofi. 


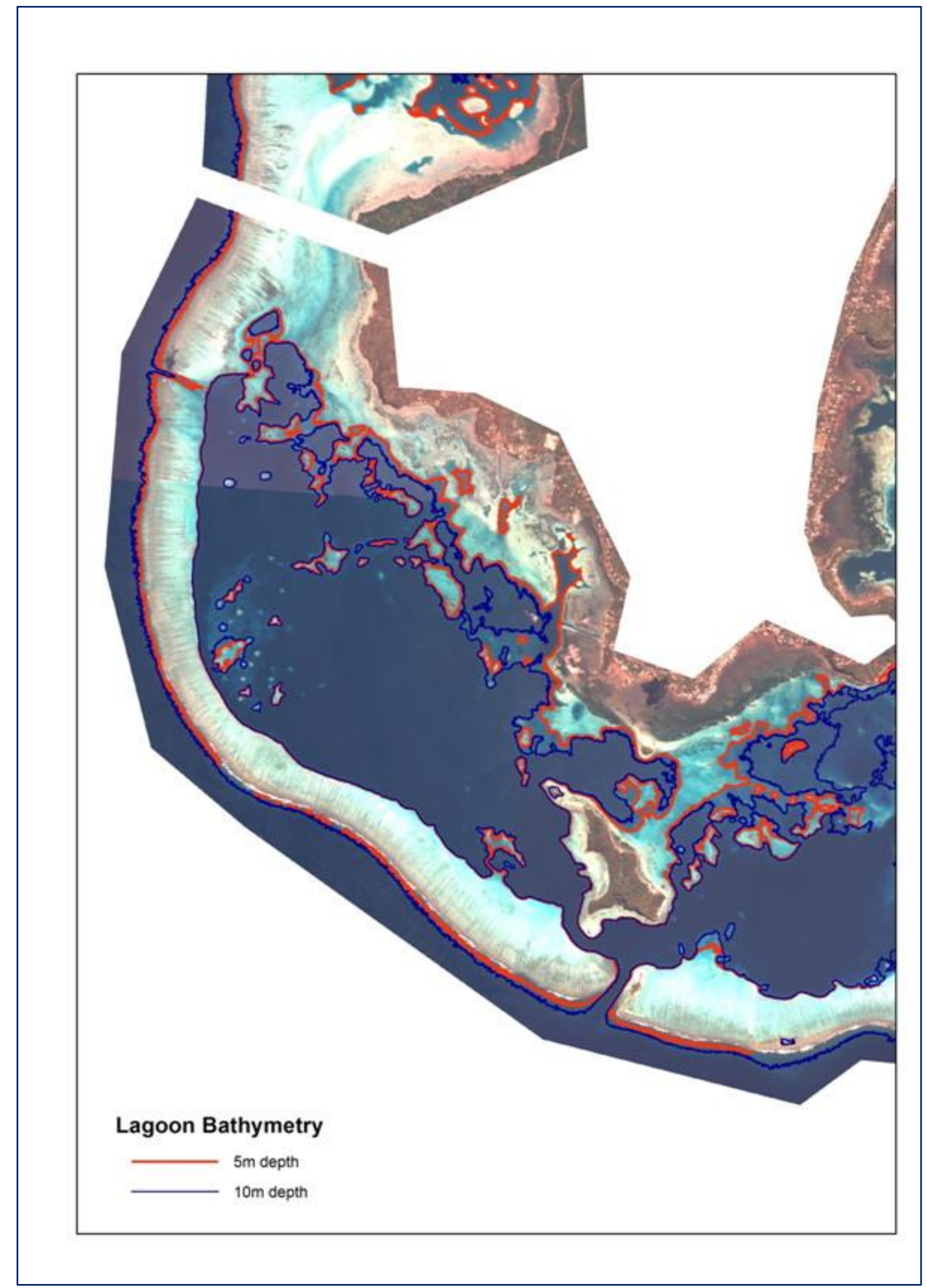

Figure 1 - Remote sensing-derived depth contours along the SW shore of Wallis Island (from Lamarche et al., 2013) 